\title{
Role of Intravenous Tranexamic Acid on Caesarean Blood Loss: A Prospective Randomised Study
}

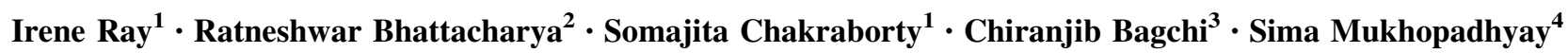

Received: 9 October 2015/ Accepted: 30 May 2016/Published online: 25 June 2016

(C) Federation of Obstetric \& Gynecological Societies of India 2016

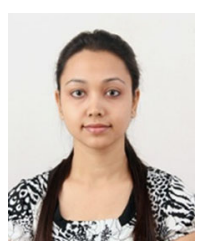

\begin{abstract}
About the Author
Dr. Irene Ray did her graduation from Medical College Kolkata in the year 2010. She completed her postgraduation, MS G\&O from the same institution in 2014. She passed DNB examination in 2015 and MRCOG (part-1) in 2013. Presently she is working in the capacity of senior resident in Medical College Kolkata. She is an active member of Bengal Obstetrics and Gynaecological society. She has published papers in national journals and presented papers at state and national-level conferences. She is a sincere, dedicated and skilful obstetrician with a kind hearted and soft-spoken personality. She is an efficient emergency surgeon and able to manage all kinds of emergency situations. Her teaching ability is admirable, too.
\end{abstract}

Dr. Irene Ray is a Senior Resident in Department of Obstetrics and Gynaecology, Medical College Kolkata; Dr. Ratneshwar Bhattacharya is an Assistant Professor in Department of Medicine, Icare Institute of Medical Science \& Research and Dr. B. C. Roy Hospital; Dr. Somajita Chakraborty is an Associate Professor, Department of Obstetrics and Gynaecology, Medical College Kolkata; Dr. Chiranjib Bagchi is an Assistant Professor in Department of Clinical and Experimental Pharmacology, School of Tropical Medicine; Dr. Sima Mukhopadhyay is a Professor in Department of Obstetrics and Gynaecology, Icare Institute of Medical Science \& Research and Dr. B. C. Roy Hospital.

Irene Ray

dr.ireneray@gmail.com

1 Department of Obstetrics and Gynaecology, Medical College Kolkata, Kolkata, West Bengal, India

2 Department of Medicine, Icare Institute of Medical Science \& Research and Dr. B. C. Roy Hospital, Haldia, West Bengal, India

\begin{abstract}
Background Post-partum haemorrhage (PPH) is a major cause of maternal mortality globally. Tranexamic acid, an anti-fibrinolytic agent, is a novel approach in an attempt to prevent this dreadful complication. This study aims to document the efficacy of intravenous (IV) tranexamic acid in reducing blood loss during and after caesarean section (CS).

Methods In this prospective randomised placebo-controlled open-label study, 100 mothers scheduled for

3 Department of Clinical and Experimental Pharmacology, School of Tropical Medicine, Kolkata, West Bengal, India

4 Department of Obstetrics and Gynaecology, Icare Institute of Medical Sciences and Research and Dr. B. C. Roy Hospital, Haldia, West Bengal, India
\end{abstract}


elective CS were randomly selected and divided into two groups (study and control) of 50 each. The study group received $1 \mathrm{~g}$ IV tranexamic acid and the control group received IV placebo. Following delivery, all mothers received ten units of oxytocin in $500 \mathrm{ml}$ of normal saline. Results The mean intra-operative and post-partum blood loss were significantly lower in the study group than the control group: $499.11 \pm 111.2$ and $59.93 \pm 12.5$ ml versus $690.85 \pm 198.41$ and $110.06 \pm 13.47 \mathrm{ml}$, respectively, $(p<0.001)$. Total blood loss was $30 \%$ less in the study group $(p<0.001)$. Six mothers had PPH in the control group, while none in the study group. The difference between the pre-operative and post-operative haemoglobin levels was significantly less in the study group than the control group, $0.26 \pm 0.22$ versus $0.99 \pm 0.48 \mathrm{~g} \%$ $(p<0.001)$.There was no significant difference with respect to other haematological parameters. There was no added adverse effect or need for NICU admission in the study group.

Conclusion Pre-operative IV tranexamic acid significantly reduced blood loss during elective CS without any significant adverse effects.

Keywords Tranexamic acid - Anti-fibrinolytics ·

Blood loss $\cdot$ Caesarean delivery $\cdot$ Post-partum haemorrhage

\section{Background}

Post-partum haemorrhage (PPH) is a major complication after both vaginal and caesarean delivery worldwide which contributes substantially to maternal mortality and near misses. Each year, about 1-2 \% of mothers with PPH die, with an average interval of about $2-4 \mathrm{~h}$ from onset of PPH to death [1]. PPH is defined as the loss of more than $500 \mathrm{ml}$ of blood following normal delivery or more than $1000 \mathrm{ml}$ loss following caesarean section [2]. There are four causes of PPH: uterine atony, trauma to the birth passage, retained placental tissue or membranes and coagulopathies such as DIC [3]. PPH can reach disastrous proportions during caesarean section.

Management of haemorrhage after CS may range from administration of oxytocics and blood transfusion to more radical measures such as hysterectomy [4, 5]. Use of antifibrinolytic agent such as tranexamic acid (TXA), however, avoids both the hazards of blood transfusion as also the long-term side effects of hysterectomy.

The aim of this study is to assess the effect of IV tranexamic acid on blood loss during and after CS.

\section{Materials and Methods}

A randomised, placebo-controlled, open-label clinical study was conducted after Institutional Ethics Committee approval, from May 2012 to April 2013 with 100 clinically stable singleton antenatal mothers (aged 20-40 years) at term scheduled for elective caesarean section. Pregnancy complications such as pre-eclampsia, polyhydramnios, macrosomia, multiple pregnancy, preterm labour, placenta praevia and abruptio placentae were excluded from the study as also mothers with blood dyscrasias, coagulation disorders, thromboembolic disorders, severe anaemia, allergy to tranexamic acid and severe medical and surgical complications involving the heart, liver or kidney.

Sample size was calculated assuming that a difference of $100 \mathrm{ml}$ of total (intra- and post-operative) blood loss would be a clinically important difference between the two groups. It was calculated that 45 subjects would be required per group in order to detect this difference with $80 \%$ power and $5 \%$ probability of type 1 error. Standard deviation was assumed to be 190 for control group and 150 for the test group on the basis of earlier study [6]. Adjusting for $10 \%$ drop out rate, recruitment target was set at 50 subjects per group. Figure 1 shows summary of study design.
Fig. 1 Summary of study design

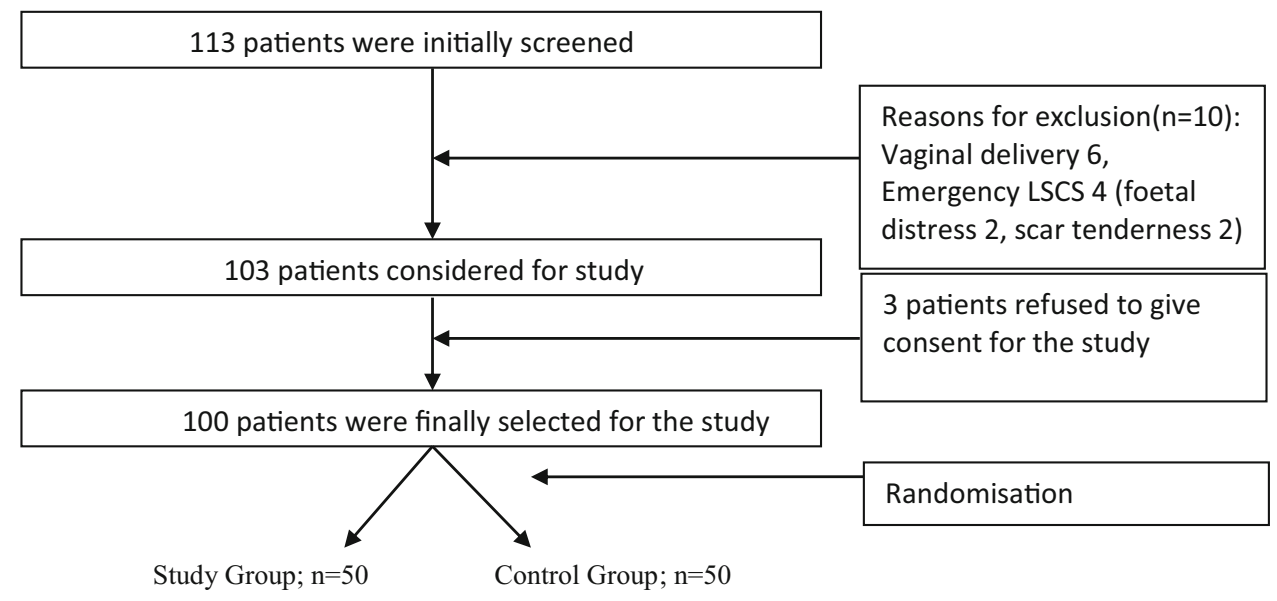


The selected 100 mothers were randomised into the two groups using a computer-generated randomisation list to receive either $1 \mathrm{~g}$ (in $10 \mathrm{ml}$ ) of intravenous (IV) tranexamic acid dissolved in $20 \mathrm{ml}$ of $5 \%$ Dextrose solution (study group; $n=50$ ) or IV placebo i.e. $30 \mathrm{ml}$ of $5 \%$ Dextrose solution (control group; $n=50$ ), 20 min before beginning of spinal anaesthesia. During CS, after draining the amniotic fluid completely and delivery of placenta, blood was drained in a separate suction container. Dry and soaked mops and sheets were weighed by a sensitive weighing machine.

Mean blood loss from mops and sheets was calculated using the formula used by Gai et al. [7]: blood from mops and sheets $=$ (weight of soaked material-weight of dry material)/1.05, where 1.05 is the specific gravity of blood at $37{ }^{\circ} \mathrm{C}$. To this, the blood drained in the suction container after delivery of placenta was added to get the total intraoperative blood loss.

After delivery 10 units of oxytocin in $500 \mathrm{ml}$ of normal saline was infused intravenously over 20-30 min. Additional 15 units of oxytocin were given post-operatively (5U in each bottle of IV fluid for three consecutive bottles over a period of $12 \mathrm{~h}$ ). Further administration of oxytocin was according to requirement. Two hour post-operative blood loss was calculated from the soaked pads by the same formula mentioned above.

Two hour post-operative vitals (pulse, systolic and diastolic blood pressure, respiratory rate and pallor) were compared with the pre-operative status in both groups. Preand $24 \mathrm{~h}$ post-operative complete blood count, coagulation profile, liver function test and renal function test were compared between the two groups.

\section{Results}

The data were expressed as mean $\pm \mathrm{SD}$, frequency and percentage. A preliminary test of normalcy (KolmogorovSmirnov test) was carried out for the distribution of the data. Numerical variables were compared with independent sample $t$ test and Mann-Whitney $U$ test, while categorical variables were dealt with Chi-square test and Fisher's exact test as appropriate. Two-tailed $p$ value $<0.05$ was considered as significant. For the data analysis, standard statistical software such as Microsoft excel, SPSS version 11.5 were utilised.

Table 1 shows that the two groups were equally matched with respect to demographic characteristics (viz. age, weight, height, gravida, parity), period of gestation at which caesarean section was done, indications for elective caesarean section, pre-operative vitals (pulse, systolic blood pressure, diastolic blood pressure, respiratory rate, pallor) and pre-operative haematological work-up such as
Table 1 Demographic characteristics and pre-operative vitals and blood work-up

\begin{tabular}{|c|c|c|c|}
\hline Parameters & $\begin{array}{l}\text { Study group } \\
(\text { mean } \pm \mathrm{SD} \text { or } \%)\end{array}$ & $\begin{array}{l}\text { Control group } \\
(\text { mean } \pm \mathrm{SD} \text { or } \%)\end{array}$ & $p$ value \\
\hline Age (years) & $25.00 \pm 4.71$ & $25.88 \pm 5.39$ & $0.387 *$ \\
\hline Weight (kg) & $65.22 \pm 5.58$ & $64.86 \pm 8.476$ & $0.803^{*}$ \\
\hline Height (m) & $1.55 \pm 0.04$ & $1.55 \pm 0.04$ & $0.889 *$ \\
\hline \multicolumn{4}{|l|}{ Gravida } \\
\hline First & $28(56 \%)$ & $31(62 \%)$ & \multirow[t]{3}{*}{$0.45^{\#}$} \\
\hline Second & $20(40 \%)$ & $19(38 \%)$ & \\
\hline Third & $2(4 \%)$ & 0 & \\
\hline Parity null & $33(66 \%)$ & $36(72 \%)$ & \multirow[t]{3}{*}{$0.48^{\#}$} \\
\hline First & $16(32 \%)$ & $14(28 \%)$ & \\
\hline Second & $1(2 \%)$ & 0 & \\
\hline $\begin{array}{l}\text { Period of gestation } \\
\quad \text { (weeks) }\end{array}$ & $38.92 \pm 1.38$ & $39.02 \pm 1.42$ & $0.722 *$ \\
\hline \multicolumn{4}{|l|}{ Indications for LSCS } \\
\hline $\begin{array}{l}\text { Post-dated } \\
\text { pregnancy }\end{array}$ & $14(28 \%)$ & $11(22 \%)$ & \multirow[t]{5}{*}{$0.945^{\wedge}$} \\
\hline CPD & $13(26 \%)$ & $14(28 \%)$ & \\
\hline $\begin{array}{l}\text { Previous } 1 \text { or } 2 \\
\text { LSCS }\end{array}$ & $9(18 \%)$ & $11(22 \%)$ & \\
\hline Mal presentations & $9(18 \%)$ & $8(16 \%)$ & \\
\hline Elderly primi & $5(10 \%)$ & $6(12 \%)$ & \\
\hline \multicolumn{4}{|l|}{ Pallor } \\
\hline Present & 22 & 29 & \multirow[t]{2}{*}{$0.161^{\wedge}$} \\
\hline Absent & 28 & 21 & \\
\hline Pulse (per minute) & $81.64 \pm 8.17$ & $84.04 \pm 6.92$ & $0.116^{*}$ \\
\hline $\mathrm{SBP}(\mathrm{mm}$ of $\mathrm{Hg})$ & $117.56 \pm 8.25$ & $116.00 \pm 8.52$ & $0.355^{*}$ \\
\hline DBP (mm of $\mathrm{Hg}$ ) & $74.12 \pm 6.08$ & $73.76 \pm 8.72$ & $0.787^{\#}$ \\
\hline $\begin{array}{l}\text { Respiratory rate (per } \\
\text { minute) }\end{array}$ & $13.64 \pm 1.39$ & $12.92 \pm 2.10$ & $0.057^{\#}$ \\
\hline $\mathrm{Hb}(\mathrm{gm} \%)$ & $10.33 \pm 1.26$ & $9.80 \pm 1.34$ & $0.050^{*}$ \\
\hline Total count (per cc) & $9250.48 \pm 1391.16$ & $9149.46 \pm 1271.68$ & $0.706^{*}$ \\
\hline $\begin{array}{l}\text { Platelet count (lacs/ } \\
\text { cc) }\end{array}$ & $2.1 \pm 0.62$ & $2.16 \pm 0.62$ & $0.589 *$ \\
\hline PT (s) & $11.86 \pm 0.17$ & $11.87 \pm 0.17$ & $0.651^{*}$ \\
\hline aPTT (s) & $31.53 \pm 0.93$ & $31.51 \pm 0.86$ & $0.894 *$ \\
\hline Bilirubin $(\mathrm{T})$ & $1.00 \pm 0.27$ & $1.04 \pm 0.25$ & $0.493 *$ \\
\hline Bilirubin (D) & $0.26 \pm 0.14$ & $0.28 \pm 0.15$ & $0.551^{\#}$ \\
\hline ALT (IU/ml) & $38.34 \pm 4.17$ & $38.92 \pm 3.99$ & $0.480^{*}$ \\
\hline AST (IU/ml) & $39.94 \pm 4.99$ & $38.18 \pm 4.86$ & $0.212 *$ \\
\hline Urea & $22.66 \pm 1.80$ & $22.52 \pm 1.78$ & $0.655^{\#}$ \\
\hline Creatinine & $0.80 \pm 0.20$ & $0.79 \pm 0.19$ & $0.805^{*}$ \\
\hline
\end{tabular}

$p$ values calculated using * independent sample $t$ test, ${ }^{\#}$ Mann-Whitney $U$ test and ${ }^{\wedge}$ Chi-square test

complete blood count, liver function tests and renal function tests.

Table 2 shows that both intra-operative and $2 \mathrm{~h}$ postoperative blood loss are significantly less in the study group than the control group.

Table 3 shows the post-operative status of the study and the control groups. Comparison of $2 \mathrm{~h}$ post-operative vitals 
Table 2 Pre- and post-operative blood loss estimation

\begin{tabular}{lcll}
\hline Parameters & $\begin{array}{l}\text { Study group }(n=50) \\
(\text { mean } \pm \text { SD) }\end{array}$ & $\begin{array}{l}\text { Control group }(n=50) \\
(\text { mean } \pm \text { SD) }\end{array}$ & Significance \\
\hline Blood volume in suction $(\mathrm{ml})$ & $98.64 \pm 28.89$ & $220.80 \pm 64.48$ & $p<0.001^{*}$ \\
Blood volume in mops + sheets $(\mathrm{ml})$ & $401.11 \pm 112.43$ & $470.05 \pm 141.07$ & $p<0.01^{*}$ \\
Blood loss-intra-operative $(\mathrm{ml})$ & $499.75 \pm 111.20$ & $690.85 \pm 198.41$ & $p<0.001^{*}$ \\
Blood loss-2 h post-operative $(\mathrm{ml})$ & $59.93 \pm 12.5$ & $110.06 \pm 13.47$ & $p<0.001^{*}$ \\
Total blood loss & $559.68 \pm 113.80$ & $800.91 \pm 200.26$ & $p<0.001^{*}$ \\
\hline
\end{tabular}

$p$ values calculated using $*$ independent sample $t$ test

Table 3 Post-operative vitals, blood work-up, APGAR score of neonate and side effects of drug

\begin{tabular}{|c|c|c|c|}
\hline Parameters & $\begin{array}{l}\text { Study group }(n=50) \\
(\text { mean } \pm \text { SD or } \%)\end{array}$ & $\begin{array}{l}\text { Control group }(n=50) \\
(\text { mean } \pm \mathrm{SD} \text { or } \%)\end{array}$ & $p$ value \\
\hline \multicolumn{4}{|l|}{ Pallor } \\
\hline Present & $24(48 \%)$ & $38(76 \%)$ & \multirow[t]{2}{*}{$0.004^{\wedge}$} \\
\hline Absent & $26(52 \%)$ & $12(24 \%)$ & \\
\hline Pulse (per min) & $83.76 \pm 7.52$ & $91.6 \pm 5.07$ & $0.000^{*}$ \\
\hline SBP (mm of $\mathrm{Hg})$ & $111.80 \pm 8.827$ & $108.6 \pm 10.184$ & $0.096^{*}$ \\
\hline DBP $(\mathrm{mm}$ of $\mathrm{Hg})$ & $68.44 \pm 6.011$ & $69.32 \pm 7.22$ & $0.753^{\#}$ \\
\hline Respiratory rate(/min) & $14.38 \pm 1.22$ & $14.00 \pm 1.71$ & $0.493^{*}$ \\
\hline $\mathrm{Hb} \%(\mathrm{~g} \%)$ & $10.08 \pm 1.18$ & $8.81 \pm 1.18$ & $0.000^{\#}$ \\
\hline $\mathrm{Hb} \%$ difference (pre-op and post-op) & $0.26 \pm 0.22$ & $0.99 \pm 0.48$ & $0.000^{*}$ \\
\hline Total count (per cc) & $9354.80 \pm 1383.91$ & $9243.20 \pm 1267.12$ & $0.675^{*}$ \\
\hline Platelet count (lacs/cc) & $1.94 \pm 0.62$ & $2.03 \pm 0.62$ & $0.493 *$ \\
\hline PT (s) & $11.78 \pm 0.16$ & $11.79 \pm 0.16$ & $0.712 *$ \\
\hline aPTT (s) & $31.78 \pm 0.91$ & $31.7 \pm 0.83$ & $0.750^{*}$ \\
\hline Bilirubin $(\mathrm{T})$ & $0.83 \pm 0.18$ & $0.86 \pm 0.19$ & $0.535^{*}$ \\
\hline Bilirubin (D) & $0.19 \pm 0.09$ & $0.21 \pm 0.10$ & $0.573^{\#}$ \\
\hline ALT & $41.18 \pm 4.95$ & $41.60 \pm 4.84$ & $0.669 *$ \\
\hline AST & $37.8 \pm 4.42$ & $38.78 \pm 4.39$ & $0.226^{\#}$ \\
\hline Urea & $22.08 \pm 1.54$ & $21.96 \pm 1.48$ & $0.739^{\#}$ \\
\hline Creatinine & $0.75 \pm 0.17$ & $0.75 \pm 0.16$ & $0.910^{\#}$ \\
\hline APGAR score $1 \mathrm{~min}$ & $7.06 \pm 1.25$ & $7.18 \pm 1.35$ & $0.559^{\#}$ \\
\hline $5 \mathrm{~min}$ & $8.66 \pm 1.00$ & $8.64 \pm 0.98$ & $0.910^{\#}$ \\
\hline \multicolumn{4}{|l|}{ Side effects } \\
\hline Nausea & $16(32 \%)$ & $13(26 \%)$ & $0.059^{\wedge}$ \\
\hline Vomiting & $9(18 \%)$ & $8(16 \%)$ & $0.790^{\wedge}$ \\
\hline Diarrhoea & $1(2 \%)$ & $0(0 \%)$ & $0.315^{\wedge}$ \\
\hline Thrombosis & $0(0 \%)$ & $0(0 \%)$ & \\
\hline
\end{tabular}

$p$ values calculated using * independent sample $t$ test, ${ }^{*}$ Mann-Whitney $U$ test and ${ }^{\wedge}$ Chi-square test

between the two groups shows that pallor $(p=0.004)$ and pulse rate ( $p=0.000$ ) were significantly lower in the study group. Systolic blood pressure, diastolic blood pressure and respiratory rate did not have any significant difference in the two groups post-operatively. Post-operative fall in haemoglobin per cent was significantly more in control $(0.99 \mathrm{~g} \%)$ group than study group $(0.26 \mathrm{~g} \%)(p=0.000)$. Other parameters, viz. total count, platelet count, prothrombin time and activated plasma thromboplastin time, bilirubin and liver enzymes, urea and creatinine, did not have any significant difference in the two groups. There was no significant difference in the APGAR values at $1 \min (p=0.559)$ and also at $5 \min (p=0.910)$ between the groups. The incidences of the adverse effects such as nausea, vomiting and diarrhoea were not significantly increased in the study group as compared to the control 
group. There was no evidence of thrombosis in any of the mothers in the study group.

\section{Discussion}

Tranexamic acid exerts its anti-fibrinolytic effect by blocking the lysine binding locus of the plasminogen and plasmin molecules, thereby preventing the binding of plasminogen and plasmin to the fibrin substrate. Tranexamic acid also inhibits conversion of plasminogen to plasmin [8]. After delivery of baby, there is transient activation of fibrinolytic cascade for 6-10 h [7]. So the efficacy of an anti-fibrinolytic agent such as tranexamic acid is being evaluated for the prevention of PPH.

The results show that intra-operatively, mothers in the study group had mean blood loss of $499.11 \pm 111.2 \mathrm{ml}$, while mothers in control group had mean blood loss of $690.85 \pm 198.41 \mathrm{ml}(p=0.000)$. Two hours post-operatively, the study group had mean blood loss of $59.93 \pm 12.5 \mathrm{ml}$, while the control group had mean blood loss of $110.06 \pm 13.47 \mathrm{ml}(p=0.000)$. Coupling the two results, mothers in the study group had mean total blood loss of $559.68 \pm 113.80 \mathrm{ml}$, while mothers in control group had mean total blood loss of $800.91 \pm 200.26 \mathrm{ml}$. Thus, in the study group, there was total reduction in blood loss by about $30 \%$ ( $p=0.000)$. Six mothers in the control group required extra ten units of oxytocin infusion, while only two of the mothers in tranexamic acid group required the same.

Movafegh et al. [6] performed their study with intravenous administration of $10 \mathrm{mg} / \mathrm{kg}$ of tranexamic acid $20 \mathrm{~min}$ before skin incision at caesarean delivery. Mean blood loss was significantly less in the tranexamic acid group compared with the control group for both intra-operative bleeding (262.5 \pm 39.6 vs. $404.7 \pm 94.4 \mathrm{ml})$ and post-operative bleeding $(67.1 \pm 6.5$ vs. $141.0 \pm 33.9 \mathrm{ml}$; $p<0.001$ ), respectively. Oxytocin administration was significantly less in the tranexamic acid group compared with the control group (39 \pm 5.8 vs. $43 \pm 5.4$ units; $p=0.001$ ). These results were consistent with the present study.

A similar study was carried out by Ming-ying Gai et al. [7] in China by administering tranexamic acid $10 \mathrm{~min}$ before skin incision. The intervention led to less bleeding $2 \mathrm{~h}$ post-operatively, $42.75 \pm 40.45 \mathrm{ml}$ in the study group versus $73.98 \pm 77.09 \mathrm{ml}$ in the control group $(p=0.001)$ but did not show any decrease in post-placental delivery blood loss. This was probably due to the fact that tranexamic acid was administered only $10 \mathrm{~min}$ before the skin incision. Thus, the present study was designed to administer tranexamic acid $20 \mathrm{~min}$ before spinal anaesthesia.

Sekhavat et al. [9] conducted a prospective randomised study on 90 primipara mothers which showed that tranexamic acid significantly reduced blood loss from the end of caesarean section to $2 \mathrm{~h}$ post-partum; $28.02 \pm 5.53 \mathrm{ml}$ blood loss in the tranexamic group versus $37.12 \pm 8.97 \mathrm{ml}$ in the control group $(p=0.000)$. These results were comparable to our study although they studied only primipara, whereas our study had no inclusion criteria based on parity.

In our study, post-operatively, there was significantly more pallor in the control group than the study group (38 vs. 24) ( $p=0.004)$. There was also significant increase in pulse, mean $84 / \mathrm{min}$ in study group versus $92 / \mathrm{min}$ in control group $(p=0.000)$. Other parameters such as systolic blood pressure, diastolic blood pressure and respiratory rate did not have any significant difference in the two groups. In the study by Movafegh et al. [6] and Gai et al. [7], there was no significant increase in pulse as also the other post-operative vitals.

There was significant difference in post-operative haemoglobin levels between the two groups, mean concentration being $10.0 \mathrm{~g} \%$ in study group versus $8.8 \mathrm{~g} \%$ in control group ( $p=0.000$ ). The difference between the preoperative and post-operative haemoglobin values was also significantly less in the study group than the control group ( $p$ value $=0.000)$. Other haematological and biochemical parameters did not have any significant difference in the two groups. These results were comparable with the study by Movafegh et al. [6] and Gai et al. [7].

Side effect profile of tranexamic acid such as nausea, vomiting and diarrhoea was similar in both groups. These results were similar to previous studies. The incidence of thrombosis during pregnancy and puerperium is 5-6 times higher than that in the general population. When the antifibrinolytic drug tranexamic acid is administered, the increased risk of thrombosis should be considered, especially in the post-partum LSCS population. In our study, however, none of the mothers developed signs of thrombosis. Svanberg et al. [10] reported 67 cases of abruptio placentae being treated by tranexamic acid without any signs of thrombosis in any. Similar results were found in other studies [6, 7, 9]. All data demonstrated that tranexamic acid can be used safely without increasing the occurrence of thrombosis, but still more studies are needed in this regard.

The safety of giving tranexamic acid ( $1 \mathrm{~g}$ ) while the foetus was still in utero was a key concern. As a consequence, the neonatal outcome was meticulously evaluated by a neonatologist. In the current study, the mean APGAR scores at 1 and 5 min were $7.06 \pm 1.25$ and $8.66 \pm 1.00$ in the study group and $7.18 \pm 1.35$ and $8.64 \pm 0.98$ in the control group. Thus, there was no significant difference in the APGAR values at $1 \mathrm{~min}(p=0.559)$ and also at $5 \mathrm{~min}$ ( $p=0.910)$ among the two groups. None of the babies required NICU admission. Results were comparable to previous studies $[6,7,9,11,12]$. 
To conclude, antenatal administration of intravenous tranexamic acid $20 \mathrm{~min}$ before spinal anaesthesia significantly reduces the amount of blood loss during and after lower segment caesarean section without any untoward adverse effects on the mother or the baby.

\section{Compliance with Ethical Standards}

Conflict of interest The authors declare that they have no conflicts of interest.

Research involving human participants and/or animals No animals were involved in this study. Only human participants were included in both case and control.

Ethical approval All procedures performed in studies involving human participants were in accordance with the ethical standards of the institutional and/or national research committee and with the 1964 Helsinki declaration and its later amendments or comparable ethical standards.

Informed Consent Written informed consent has been taken from all patients participating in the trial.

\section{References}

1. AbouZahr C. Antepartum and postpartum haemorrhage. Chapter 4. First edition. Boston, Geneva: Harvard School of Public Health on behalf of the World Health Organisation and the World Bank; 1998.

2. Magann EF, Evans S, Hutchinson M, et al. Postpartum haemorrhage after cesarean delivery: an analysis of risk factors. South Med J. 2005;98(7):681-5.
3. Combs CA, Murphy EL, LarosJr RK. Factors associated with haemorrhage in cesarean deliveries. Obstet Gynecol. 1991;77(1):77-82.

4. Munn MB Owen J, Vincent R, et al. Comparison of two oxytocin regimens to prevent uterine atony at cesarean delivery: a randomized controlled trial. Obstet Gynecol. 2001;98:386-90.

5. Hofmeyr GJ, Walraven G, Gulmezoglu AM, et al. Misoprostol to treat postpartum haemorrhage: a systematic review. BJOG. 2005;112:547-53.

6. Movafegh A, Eslamian L, Dorabadi A. Effect of intravenous tranexamic acid administration on blood loss during and after caesarean delivery. Int J Gynaecol Obstet. 2011;115:224-6.

7. Gai MY, Wu LF, Su QF, et al. Clinical observation of blood loss reduced by tranexamic acid during and after caesarian section: a multi-center, randomized trial. Eur J Obstet Gynecol Reprod Biol. 2004;112(2):154-7.

8. Thorsen S, Clemmenson I, Sottrup-Jensen L, et al. Adsorption to fibrin of native fragments of known primary structure from human plasminogen. Biochim Biohys Acta. 1981;668:377-87.

9. Sekhavat L, Tabatabaii A, Dalili M, et al. Efficacy of tranexamic acid in reducing blood loss after cesarean section. J Matern Fetal Neonatal Med. 2009;22(1):72-5.

10. Svanberg L, Astedt B, Nilsson IM. Abruptio placentae treatment with the fibrinolytic inhibitor tranexamic acid was effective. Acta Obstet Gynaecol Scand. 1980;59:127-30.

11. Shakur H, Elbourne D, Gülmezoglu M, et al. The WOMAN Trial (World Maternal Antifibrinolytic Trial): tranexamic acid for the treatment of postpartum haemorrhage: an international randomised, double blind placebo controlled trial. Trials. 2010;16(11):40. doi:10.1186/1745-6215-11-40.

12. Gungorduk K, Yildirm G, Asicioğlu O, et al. Efficacy of intravenous tranexamic acid in reducing blood loss after elective cesarean section: a prospective, randomized, double-blind, placebo-controlled study. Am J Perinatol. 2011;28(3):233-40. 